\title{
Ética y tecnología. Algunos problemas actuales
}

\author{
P.F. Martínez-Austria \\ Coordinador de Asuntos Fronterizos, Comisión Nacional del Agua \\ Facultad de Ingeniería, UNAM \\ E-mail:polioptro.martinez@cna.gob.mx
}

(recibido: marzo de 2002; aceptado: diciembre de 2002)

\section{Resumen}

En este trabajo se analiza la relación de la ética y la tecnología utilizando un enfoque deductivo. Asimismo, a partir de una rápida visión de algunos aspectos de la situación de la civilización posmoderna y de su percepción de la tecnología, se analiza la relación entre la tecnología y la valoración ética del mundo, de esta forma, se propone una apreciación ética positiva de la tecnología. Finalmente, se revisan algunos de los principales problemas que el desarrollo tecnológico plantea hoy a la ética, como la manipulación genética, la conservación del medio ambiente y la pobreza extrema. El propósito de este trabajo es contribuir, desde el punto de vista de un tecnólogo, al análisis de un tema que hoy, más que nunca, debe formar parte del acervo cultural de los ingenieros. El autor reconoce las dificultades de un estudio interdisciplinario como el que aquí se aborda, y no se propone obtener conclusiones o recomendaciones, solamente propiciar la reflexión sobre la relación entre ética y tecnología, así como algunos de sus problemas actuales.

Descriptores: ética y tecnología, ética e ingeniería.

\section{Abstract}

In this work it is analyzed the relationship of the ethics and the technology, using a deductive focus. The social perception of technology, producing social development and well-being but also causing conflicts and danger, force a revision of their ethics, in which the engineers must take part. In this paper the relationship of the ethics and the technology is analyzed, using a deductive approach. Starting from a broad vision of some aspects of the situation of the postmodern civilization and of their perception of the technology, the relationship between technology and the ethical valuation of the world is analyzed, and a positive ethical appreciation of the technology is intended. Finally, some main problems that the technological development outlines today to the ethics, are revised: the genetic manipulation, the environmental conservation and the extreme poverty alleviation. The purpose of this work is to contribute, from the point of view of a technologist, to the analysis of a topic that today, more than ever, it should be part of the engineers' background. The author recognizes the difficulties of an interdisciplinary study as the one that here is approached, and he doesn't intend to obtain conclusions or recommendations, but to promote the thinking on the technology and ethics relationship, and on several of their actual problems.

Keywords: ethics and engineering, ethics and technology. 


\section{Introducción}

El análisis de la relación entre la ética y la tecnología debe abordarse como una necesidad de nuestro tiempo, que ha sido lacerado con frecuencia por la desvinculación entre los resultados que la tecnología produce y las metas legítimas del hombre. Este trabajo se ha escrito con este espíritu y con la convicción de que es importante abrir el tema y participar en su discusión, ya que a todos nos afecta. Esta presentación se ha planteado con un método deductivo; desde una revisión general de algunos aspectos de nuestra civilización, a los principales campos de problemas éticos en la tecnología actual. No puede ser de otra manera, porque en medio de la confusión actual, pocas cosas se pueden dar por sentadas.

\section{La crisis de la civilización}

¿Cuál es el marco general en el que se ubica este análisis? Alejados más o menos de las principales corrientes culturales de nuestra época, vivimos sin embargo en la posmodernidad, que se caracteriza entre otros aspectos por la disolución de la permanencia del ser y de la noción de la historia como progreso, por la crisis de la verdad, la negación de todo absoluto, la crisis de la racionalidad, la crisis del humanismo y muerte de Dios en la conciencia y el corazón del hombre (Ruiz, 1996). Siguiendo algunos modernos intelectuales presti- giados, se describirán algunos elementos de esta sociedad posmoderna que se relacionan especialmente con la ética de la tecnología, aclarando que estos rasgos son globales, aunque se noten más en los países ricos de Europa y América del Norte.

La crisis a la que asistimos es de enormes proporciones. Muchos intelectuales afirman sin ambages que vivimos en una sociedad profundamente decadente, que ha alcanzado niveles inauditos en su hundimiento, al punto que algunos lo consideran irreversible (Latourelle, 1997). Muchos autores identifican el inicio de esa decadencia con el nacimiento del racionalismo y la ilustración, concretamente con Voltaire y la Enciclopedia en el siglo XVIII.

Siguiendo las ideas de Latourelle, se puede afirmar que entre los rasgos dominantes de esta sociedad, destaca en primer término, la ausencia del Absoluto. Como lo anunciaran Nietzche, Freud y Marx, Dios -en un sentido tanto cultural como espiritual- ha muerto en la conciencia de los hombres. No se admite siquiera la posibilidad de lo Absoluto, y por ello, lo que se encuentra es el relativismo y la indiferencia. Con esto, Occidente ha perdido sus valores: la familia ya no es el centro de la estabilidad emocional de los seres humanos, el trabajo se redujo a productividad, la autoridad se concibe como un factor de parálisis y la verdad se ha relativizado de tal modo que, con demasiada frecuencia, se confunde con la mentira e hipocresía.
En este contexto cultural, los ingenieros y los tecnólogos han participado ampliamente en lo relativo al concepto de progreso, el cual domina en nuestra época, pero también en crisis y, definitivamente, ha sido declarado como un concepto pervertido. Algunos tecnólogos se han transformado en tecnócratas y han convertido a la tecnología en enemiga del hombre, destructora del medio ambiente y permanente amenaza en las guerras de nuestros días. Este siglo XXI, es también la era de la violencia tecnológica. Cada momento se libran una treintena de conflictos armados de diversa magnitud.

Finalmente, la sociedad occidental, en particular en los países más desarrollados económicamente, en gran parte es hedonista: el generalizado culto del placer no tiene precedente histórico.

Sin embargo, en medio de este panorama hay razones para la esperanza como la democratización de numerosos países, los grupos defensores de los derechos humanos, las organizaciones ciudadanas de tipo asistencial que hacen de la solidaridad su método, la existencia y actuación de organizaciones internacionales como el Programa de Naciones Unidas para el Desarrollo, La Organización de las Naciones Unidas para la Agricultura y la Alimentación, o la Organización Internacional del Trabajo; también la emergencia de nuevas tecnologías respetuosas del hombre y del medio ambiente y los 
movimientos ecologistas que defienden el mismo, así como el patrimonio de las futuras generaciones. No obstante, estos esfuerzos son aún incipientes y requieren de un refuerzo desde todas las trincheras posibles.

La civilización evoluciona rápidamente a una más renovada, con detalles aún poco reconocibles. Un paso indispensable en la construcción de una nueva sociedad, es la recuperación de los valores. Rodríguez (1999) reconoce, por ejemplo, que "los valores de la sociedad tradicional -los de "nuestra" sociedad tradicional, habría que decir- han quebrado, pero no lo han hecho los valores que cimientan toda civilización, ya que de alguna manera son valores permanentes, de siempre. Por eso, la construcción de una nueva civilización o de una nueva cultura no podrá hacerse sin volver a ellos". Ése es uno de los cometidos de la ética.

\section{Valoración ética del mundo y tecnología}

Existen dos concepciones radicalmente distintas de la ética (Abbagnano, 1961), la primera, y que será la que se adopte en esta exposición, la considera la ciencia del fin y de los medios para alcanzarla, y el fin, no es otro que la propia naturaleza del hombre, vista en su plenitud. La segunda visión de la ética es la que la considera la ciencia del impulso, de la motivación de la conducta humana. Para la primera, el bien se identifica con un ideal de perfección-el bien es la felicidad-, para la segunda, el bien es el placer. La primera visión de la ética considerará que alcanzar la felicidad es el fin de la conducta humana, y la segunda pretenderá que el placer es el móvil de esa conducta.

Si se sitúa al hombre y su felicidad como el propósito de la vida, entendida la felicidad como la condición en que cada ser humano hace más plena su propia naturaleza, entonces la técnica tendrá como objetivo ayudar a los seres humanos a alcanzar este propósito, que es: en el ámbito individual, lograr su más pleno desarrollo humano, y en lo colectivo, humanizar a la sociedad. Así también, a nivel de lo natural, preservar el medio ambiente de forma que los hombres de las futuras generaciones no vean coartado su propio derecho a la felicidad.

Si el bien se concibe de esta manera, es legítima la pregunta ¿En qué grado la ciencia y la técnica han contribuido al bien de la humanidad? La técnica aquí, la entenderemos en el sentido aristotélico (Aristóteles, Met. $1070^{a}$ ) como el arte de todo lo que el hombre produce artificialmente, en oposición a lo natural. Interesa, sin embargo, el efecto de la técnica moderna, a la que se hará referencia en adelante de manera exclusiva.

En su nacimiento en el siglo XVII, y sobre todo, desde la revolución industrial del siglo XVIII, la técnica moderna pareció prometer a los hombres la capacidad -el poder- de dominar la naturaleza para alcanzar la satisfacción de sus necesidades elementales. La tecnología, como la entendía Bertrand Russell en su famoso libro "La perspectiva científica" es la ciencia como poder, muy diferente a la ciencia básica, que sería la ciencia como conocimiento.

A los tecnólogos-científicos o ingenieros- se les deben reconocer los grandes logros de la técnica moderna como el aumento de la producción de alimentos, de la longevidad y de la salud, así como la disminución del dolor, por citar algunos. Sin embargo, estos logros no han alcanzado a todos, por lo que tenemos que reconocer que el poder de la tecnología no se ha utilizado con plena responsabilidad, al grado de que hoy en día, se plantea como un escenario posible el que sea un elemento ejecutor que conduzca a la destrucción. Ya no se trata solamente del peligro nuclear que desde los años cincuenta nos acompaña; ahora se añade el riesgo de una catástrofe ecológica global. Desafortunadamente, ambas posibilidades son reales.

Así, a diferencia del sueño ingenuode progreso ilimitado que parecía prometer, hoy coexisten dos visiones de la tecnología: una que la ve como un peligro, y otra como el mejor medio del hombre moderno para alcanzar la felicidad. Los primeros, que la observan con desconfianza, propugnan por su control, y entre los más extremistas, incluso por la vuelta a 
una era pretecnológica, a la manera de los asrams de Ghandi. Los segundos, reconociendo los problemas que la tecnología ha causado, los consideran efectos colaterales y confían que la propia investigación científica y tecnológica será suficiente para corregirlos y revertirlos.

En el fondo de ambas posiciones, subsiste un problema más profundo que es preciso explicitar: dos visiones del mundo, una negativa y otra positiva, que a lo largo de la historia se han confrontado en diferentes culturas y que se han de considerar para comprender la relación entre ética, tecnología y sociedad. Esto debe tenerse en cuenta para establecer los puntos de partida de una ética de la tecnología.

En primer término, se hará referencia a la visión pesimista del mundo que fluye ácidamente a lo largo de la historia. En la tradición judía, esta idea pesimista del mundo se observa en algunos libros sapienciales (escritos alrededor del siglo II antes de Cristo), especialmente en el libro de Qoéhelt (o Eclesiastés). En la tradición griega, esta es la visión del platonismo, que ve en el mundo natural un reflejo grosero y un lastre para lo espiritual que será lo verdadero (el cristianismo no estará exento de contaminarse de estas ideas, que producen de vez en vez espiritualismos exacerbados). En las tradiciones orientales, algunos conceptos del budismo podrían tomarse como el paradigma de esta visión negativa del mundo. Vale la pena recordar las cuatro verdades -aryastyanique según el sermón de Benarés forman la ley budista suprema:

1. Todo lo que existe está sujeto al dolor.

2. El origen del dolor reside en los deseos humanos.

3. La supresión del dolor proviene de la supresión de los deseos.

4. El método moral para llegar al nirvana es la eliminación de todo deseo (Riviere, 1984).

Todas estas posiciones pesimistas con respecto al mundo y que recorren las diversas culturas, son difícilmente compatibles con una ética de la tecnología. ¿Cómo puede ser éticamente correcto trabajar para mejorary hacer más agradable el mundo, si la primera regla de tal modo de pensamiento es despreciarlo? Es principalmente a partir de estas visiones del mundo que hoy se critica más a la tecnología.

Afortunadamente, también existe una tradición con una visión optimista del mundo, la judeo-cristiana que se encuentra en la narración de la creación del Génesis. En este texto, cada día de la creación termina con la frase "y vio Dios que era bueno". En esta visión se ve al mundo y al hombre como esencialmente buenos, con un destino positivo, aunque no sea por ahora completamente evidente. Esta misma visión se encuentra en la filosofía medieval, especialmente en Tomás de Aquino, que desarrolla una teología positiva de la creación: "suprimir el orden de las cosas creadas es quitarles lo mejor que tienen; pues cada una es en sí misma buena, pero todas juntas son óptimas por razón del orden universal" (Suma contra los gentiles). Es la misma visión de Francisco de Asís, expresada en su famoso "cántico a las criaturas".

Esta visión optimista del mundo y del hombre, busca transformar la naturaleza, ha impulsado a la ciencia y la técnica y debe ser una característica fundamental de la ética de la tecnología. Así, se puede valorar a la tecnología como básicamente buena, aún en medio de los graves abusos que de ella se han hecho. Si bien precisamente por ellos, la responsabilidad de los tecnólogos de nuestra generación es aún mayor.

\section{Tecnología y problemas de la etica especial}

Refiriéndose a la ética, Riecken (1987) señala que las cuestiones apremiantes de nuestro tiempo no ocurren en la ética general, sino que se encuentran en los campos de la ética especial.

¿Cuáles son los problemas especiales a que se enfrenta hoy la ética de la tecnología? En general, se confrontan a nivel global tres problemas muy importantes: el medio ambiente, la manipulación genética y la desigualdad social. En seguida, se abundará en estos problemas. 


\section{Ética, tecnología y manipulación genética}

Una de las ramas más recientes de la tecnología es la ingeniería genética. Es en esta disciplina donde se plantean ahora algunos de los mayores problemas éticos. ¿Hasta qué punto es éticamente aceptable la manipulación genética de especies diversas y, en último término, del propio ser humano? Pocos estarán enterados en detalle de los resultados de este proyecto internacional que tiene el potencial de producir la mayor revolución científica y social de toda la historia: el proyecto genoma humano. En primer término, es necesario aclarar que por genoma se entiende toda la información genética de una especie en particular. El proyecto genoma humano tiene como propósito descifrar, clasificar y conocer toda la información genética de los seres humanos.

El proyecto comenzó en 1990 , con la coordinación del Departamento de Energía y los Institutos Nacionales de Salud de los Estados Unidos. Es una investigación que se planteó con una duración de 15 años y que hace posible determinar los 80,000 genes que componen el DNA de los seres humanos y los tres billones de secuencias que lo constituyen, guardando la información en bases de datos. Hoy, este proyecto está prácticamente terminado.

Algunos problemas éticos fundamentales surgen a la vista: ¿Puede alguien solicitar un examen genético como requisito para ejercer algún trabajo, contraer matrimonio, buscar un puesto público, etc.? ¿Cuál será el impacto psicológico causado a los individuos cuando conozcan sus "deficiencias genéticas"? ¿La información genética de los individuos deber ser privada? ¿Es de esperarse algún tipo de "discriminación por razones genéticas"? Una vez iniciada la manipulación genética ¿Se podrán patentar los nuevos genes? La existencia de anomalías genéticas muy probablemente cambiará nuestro concepto de salud y enfermedad. Para mayor claridad conviene plantear alguna situación que puede ocurrir en la realidad: Se considera que una persona tiene retraso mental cuando su coeficiente de inteligencia es inferior a $70 \circ 75$. E1 $90 \%$ de las personas con retraso tienen un IQ entre 50 y 75. La causa de este problema es múltiple y en buena medida desconocida, pero ya se han determinado más de 750 desórdenes genéticos que pueden causar retraso mental. Cuando llegue el día en el que un individuo se pueda hacer un estudio completo de su material genético ¿Cuál será la probabilidad de que tenga uno de estos desórdenes genéticos? Si se identifica uno de ellos, al menos, su reacción emocional puede ser impredecible, tal vez tendrá problemas de autoestima -por decir lo menos-, tal vez se autolimite para procrear descendientes, y si esta información se divulga, ¿Cómo afectará a su pareja? No son problemas sencillos y es legítimo preguntarse si la ciencia tiene derecho a investigar y manipular nuestro más preciado patrimonio: la herencia genética.

La posibilidad de que el genoma humano de cada individuo, el del lector y el del que escribe se conozca y manipule, es tan real que la UNESCO ha intervenido en el asunto, y en noviembre de 1997 emitió la "Declaración Universal sobre el Genoma Humano y los Derechos Humanos", en el que quedan consagrados nuestros derechos en 25 artículos. Entre ellos, destaca el segundo en el que se cita que "Cada individuo tiene derecho al respeto de su dignidad y derechos, cualesquiera que sean sus características genéticas" y que "esa dignidad impone que no se reduzca a los individuos a sus características genéticas". En su artículo quinto se establece que "en todos los casos (de investigación, tratamiento o un diagnóstico en relación con el genoma de un individuo), se recabará el consentimiento previo, libre e informado de la persona interesada".

Entramos ya al tema más controvertido de la ingeniería genética: La clonación de especies superiores $y$, eventualmente, del ser humano. Tal vez algunos piensen que esa es una probabilidad remota, que los científicos y tecnólogos - seguramente- no se atreverían a realizar clones humanos. La experiencia muestra que en la ciencia ocurre precisamente al 
revés: si algo es remotamente posible, se hará lo necesario para lograrlo -todo es cuestión de tiempo y recursos económicos-. En el número correspondiente a junio de 1998 de la revista Ciencia, de la Academia Mexicana de Ciencias, el filósofo Rodolfo Vázquez publica un artículo cuyo propósito es justificar éticamente la clonación. La propia Academia Mexicana de Ciencias realizó una encuesta entre sus miembros (Lisker y Tapia, 1997). Se les preguntó si sabían en qué consiste la clonación, si estarían de acuerdo en que se continuara la investigación sobre la clonación en mamíferos, incluyendo seres humanos, para solucionar un problema médico o social, por ejemplo la esterilidad, - para conocer más a fondo la biología celular y los mecanismos de la expresión genética. Finalmente, se les cuestionó si estaban de acuerdo en que, en principio y una vez superados los problemas técnicos que aún existen, se realizara la clonación de humanos; el $65 \%$ estuvo en contra, el 15\% se declaró indeciso, y e1 20\% estuvo de acuerdo. Las cifras hablan por si mismas. La clonación y la manipulación genética de mamíferos será un procedimiento común en el futuro, y la manipulación genética y la clonación de seres humanos se verá como aceptable en determinadas circunstancias. Es un tema delicado en el que debemos participar, al menos en la vigilancia de la aplicación éticamente correcta de la ingeniería genética ${ }^{1}$.

\section{Ética, tecnología y medio ambiente}

Tal vez estos problemas parecerán lejanos a la mayoría de los ingenieros. Más cercano a ellos está el segundo gran problema de nuestra época en el que se plantean graves problemas éticos para los tecnólogos: la relación de la ingeniería con el medio ambiente. Es aquí donde el poder de la técnica se ha mostrado capaz de modificar de manera sustancial a la naturaleza. Aparte de que cada día desaparecen nuevas especies, se ha alterado de tal modo el contenido de gases de la atmósfera que todo parece indicar, se está causando un calentamiento global del planeta. Las obras que más enorgullecían a los ingenieros, las presas y las carreteras, son ahora de las más cuestionadas. Se afirma que las grandes presas ocasionan cambios irreversibles e inaceptables en el medio ambiente, disminuyendo o cortando el flujo natural en los cauces. Se sabe que las grandes presas son, incluso, capaces de producir sismos locales hasta de cuarto grado, sin considerar el riesgo de falla de estas obras. Hasta hace poco se pensaba que las centrales hidroelécticas causaban, comparativamente, poco daño al medio ambiente al no consumir el agua, sino sólo retenerla temporalmente. Hoy se sabe que, a menos que se hagan obras adicionales para evitarlo, el agua que se extrae de ellas, por provenir del fondo, sale de regiones eutroficadas con elevados valores de DBO (Demanda Biológica de Oxígeno). Asimismo, los cambios bruscos de flujo en el cauce aguas abajo, ocasionados por su operación para satisfacer las demandas pico, se sabe hoy que afectan a los alebines y pueden ocasionar una disminución en la población de peces en los ríos. En este contexto, cada vez que se proponga una nueva obra que pueda alterar el medio ambiente, asî sea en pequeña escala, es un deber ético revisar si no se producirá un daño importante o irreversible al medio ambiente, evaluar sus efectos y tomar la decisión en conjunto con la sociedad.

Sin embargo, el mayor cambio al ambiente ya se ha producido y sus efectos se extenderán, al menos, durante un siglo: el calentamiento global. Este se produce por el incremento de gases de invernadero en la atmósfera, fundamentalmente carbono. Se prevé que se incrementará la temperatura promedio de la Tierra, lo cual a su vez producirá efectos muy graves en el ciclo hidrológico, aumentando las necesidades hídricas de los cultivos y alterando la precipitación y el escurrimiento.

La ONU estableció un Panel Intergubernamental para el estudio de este problema global,

\footnotetext{
1 Para informarse de los últimos avances del proyecto del genoma humano, se recomienda visitar la página web http://www.ornl.gov/hgmis "Human Genome Project Information".
} 
denominado IPCC (por International Panel for Climate Change). El grupo de trabajo correspondiente al estudio científico del cambio climático, determinó que se registraban incrementos sustanciales de los gases de invernadero presentes en la atmósfera, debido a las actividades humanas, en particular, desde la era industrial y que estos incrementos intensificarían el efecto natural de invernadero (Houhghton, 1991). Se plantearon diversos escenarios y utilizando modelos de circulación global, se evaluaron los efectos en esos escenarios. En todos ellos se pronosticaron incrementos en la temperatura, con los consecuentes cambios en la precipitación y el escurrimiento.

Desde entonces, se ha desarrollado una abundante investigación en el tema, fundamentalmente en las siguientes líneas de trabajo: determinación de las emisiones de gases de invernadero (inventario de gases de invernadero), mejoramiento de los modelos globales, colección de datos, y establecimiento de posibles efectos del calentamiento global, medidas de mitigación y medidas de adaptación.

En 1995, el grupo de trabajo dedicado al estudio de los impactos, medidas de adaptación y mitigación, publicó un segundo informe (Watson et al., 1995) en el que precisa que en promedio cabe esperar un incremento de la temperatura de entre 1 a $3.5^{\circ} \mathrm{C}$ y un incremento del nivel medio del mar de entre 15 y $95 \mathrm{~cm}$. El tercer reporte de vulnerabilidad (Manning y Noble, 2001), en donde se recopila la más reciente información sobre el tema, ha concluido estimaciones más pesimistas; para el año del 2100 la concentración de $\mathrm{CO}_{2}$ se elevará entre 478 ppmv y 1099 ppmv, la temperatura media de la Tierra se incrementará entre $1.4^{\circ} \mathrm{C}$ y $5.8^{\circ} \mathrm{C}$ y el nivel medio del mar aumentará entre 9 y $88 \mathrm{~cm}$. Los efectos sobre la precipitación serán variables, dependiendo de la región de que se trate, si bien, son necesarios estudios regionales, dado que a ese nivel los resultados de las simulaciones con modelos globales necesitan ser refinados. No obstante, el grupo de trabajo II del IPCC estima que, a pesar de estas incertidumbres, "se han identificado cambios con un potencial serio, incluyendo, en algunas regiones, un incremento en la incidencia de eventos extremos de altas temperaturas, inundaciones y sequías, con las consecuencias de incendios, epidemias, y composición, estructura y funcionamiento de los ecosistemas, incluyendo productividad primaria".

De acuerdo con el reporte del grupo II del IPCC, los cambios en el ciclo hidrológico y en el manejo de los recursos hidráulicos serán de enorme importancia. El documento indica que "el cambio climático producirá una intensificación del ciclo hidrológico global y tendrá impactos importantes en los recursos hidráulicos globales y regionales. Cambios en el volumen y distribución del recurso hidráulico afectarán los abastecimientos de agua superficial y subterránea para usos doméstico, industrial, irrigación, generación de energía, navegación, caudal ecológico y usos recreativos".

No obstante, la estimación de los efectos del cambio climático en los recursos hidráulicos ha resultado muy difícil de realizar. El primer esfuerzo internacional para analizar este problema se realizó en 1986, mediante un simposio internacional, cuyos resultados fueron publicados por Solomon et al. (1987). En ese año, la Organización Meteorológica Mundial puntualizaba que había muy pocos artículos publicados en el tema (Askew, 1987). Diez años después, el Secretario General de la OMM, G.O.P. Obasi (1997), recomendó como una de las estrategias prioritarias para hacer frente al efecto del cambio climático en los recursos hidráulicos, que "se promoviera la investigación relativa al impacto potencial del clima, la variabilidad climática y el cambio climático sobre los recursos hidráulicos de una región o cuenca hidrológica, y que se haga uso de esta información cuando se planee el aprovechamiento de estos recursos".

Los efectos negativos del cambio climático en la disponibilidad de agua se sumarán al incremento de la población y a una mayor competencia por un 
recurso cada vez más escaso. Así, el cambio climático exacerbará la problemática futura de escasez y hará no sustentable el desarrollo de algunas regiones. En México, las regiones con mayor riesgo serán las zonas agrícolas asentadas en el norte y centro, con climas árido y semiárido (Martínez et al., 1995, 1996y 1998).

En este campo, el proceder ético de los tecnólogos debe considerar la adopción de un compromiso real para conocer, asimilar y poner en práctica medidas de prevención y atenuación de los efectos del calentamiento global y, en general, adoptar y ejercer los principios del desarrollo sustentable. Es también un deber ético alertar a la población sobre los riesgos del calentamiento global, y las medidas que cada ciudadano puede adoptar para atenuar sus efectos.

\section{Ética, tecnología y pobreza extrema}

El tercer gran problema de la ética especial con el que la técnica tiene que ver, es el de la inequidad social, que en nuestro país se manifiesta en la existencia de 40 millones de personas que viven en la pobreza, que se observa sobre todo en el medio rural. En México existen, de acuerdo con INEGI, 201,138 comunidades rurales. De ellas, sólo alrededor del 12\%, en 1992 , tenía servicios de saneamiento básico, y menos de la mitad cuentan con abastecimiento de agua potable. En esas zonas rurales viven alrededor de 24.15 millones de habitantes. Así, estamos hablando de millones de personas en este país que no cuentan con los más elementales servicios: agua y saneamiento.

Definitivamente, en esta situación los tecnólogos tienen mucho por hacer, y la conducta ética apropiada será sin duda el contribuir de todas las maneras posibles, a revertir esta situación. He aquí algunas sugerencias: las organizaciones gremiales podrían brindar asesoría y apoyo a estas comunidades, algunos ingenieros -como hacen algunos médicos-podrían dedicar una parte de su tiempo al año para colaborar con ellas, los investigadores en las universidades podrían dedicarse a desarrollar tecnologías apropiadas para estas condiciones, aunque no se puedan publicar en "revistas de reconocido prestigio y con arbitraje internacional".

Desde luego, una de las mayores dificultades en la generación de tecnologías para atacar la pobreza extrema, es la carencia de fondos para la investigación aplicada en este cam po. Por ejem plo, a lo largo del siglo pasado se han dedicado enormes cantidades de dinero al desarrollo de sistemas de riego y cultivo para grandes extensiones de tierra. Todos han visto las imágenes de enormes tractores o cosechadoras, o sistemas de riego de pivote central que cubren enormes extensiones, por mencionar algunas tecnologías de gran impacto. Sin embargo, en México, la superficie promedio de tenencia de la tierra es de poco más de dos hectáreas por propietario. Para cultivar adecuadamente estas pequeñas superficies, no hay aún, por increíble que parezca, la tecnología de riego apropiada (Postel et al., 2001).

\section{Conclusiones}

En temas tan complejos no es posible, ni es el objeto de este ensayo, obtener conclusiones que serían sin duda controvertidas. A manera de consideración final, se puede decirque aunque el panorama actual del desarrollo tecnológico y su impacto social se ve ensombrecido por graves problemas con una fuerte componente ética, el primer paso en la solución de esta problemática es reconocer su existencia en toda su profundidad, y abrir el tema a la discusión ética. En segundo término, mantener una postura optimista, de confianza en la capacidad de los ingenieros y en el propio desarrollo tecnológico para contribuir a su solución - misma que por supuesto no depende exclusivamente de estos profesionales-cuidando que se produzca una gestión rigurosamente ética de la tecnología hacia los grandes conflictos actuales, algunos de los cuales se han bosquejado en este texto. Finalmente, cada ingeniera e ingeniero debe sopesar en el futuro, ahora más que nunca, las implicaciones éticas de su ejercicio profesional. 


\section{Referencias}

Abbagnano N. (1961). Diccionario de filosofía. Fondo de Cultura Económica. México.

Houghthon J.J. (1991). Scientific Assesment of Climate Change: Summary of the IPCC Working Group I Report, en Climate Change: Science, impacts, and Policy. OMM. Cambrige University Press.

Latourelle R. (1997). Una llamada a la esperanza. Editorial Sígueme. Salamanca. España.

Lisker R. y Tapia R. (1997). Clonación en humanos. Ciencia, Vol. 48, No. 3, Septiembre. Academia Mexicana de Ciencias. México DF, 5-13. Manning M. y Noble C. (2001). Impacts, Adaptation and Vulnerability. Technical Summary. Report of the Working Group II of the IPCC. WMO.

Martínez-Austria P. y Mundo M.M. (1995). Climate Change Effects on Yaqui Valley Agriculture. Management of Water Resources in North America III. Anticipating the 21 st century. American Society of Civil Engineering.
Martínez-Austria P., Hernández L. y Mundo M.M. (1996). Climate Change and its Effects on Agricultural Production in Northern Mexico. Proceedings of the 6th International Conference on Computers in Agriculture, held in Cancun, México, 11-14, June.

Martínez-Austria P., Hernández L. y Mundo Molina M. (1998). Global Warming Effects on the Water Balance in México. $7^{\text {th }}$ International Conference on Computers in Agriculture. Florida, october 26-30 th , ASAE, The Society for Engineering and Agricultural, Food and Biological Systems.

Postel S., Polak P., González F. y Séller J. (2001). Drip Irrigation for Small Farners: A New Initiative to Alleviate Hunger and Poverty. Water International, Vol. 26, No. 1, 3-13.

Riecken F. (1987). Ética general. Editorial Herder. Barcelona, España.

Riviere J.R. (1984). Budismo. En el mundo de las religiones. Tomo II. Editorial Marín. Barcelona, España.
Rodríguez-Arana M. J. (1999). La ética y el hombre. Papeles de ética, economía y dirección. No. 4. Madrid. España.

Ruiz-Rodríguez V. (1996). Ética y mundo actual. Cuaderno de Filosofía No. 29. Universidad Iberoamericana. México, DF.

Solomon S.I., Beran M. y Hogg W.Ç, Editores (1987). The Influence of Climate Change and Climate Variablity on the Hydrological Regime and Water Resources. IAHS Publication, No. 168

Unesco (1997). Declaración Universal sobre el Genoma Humano y los Derechos Humanos. XXIX Reunión de la Conferencia General. París, Francia.

Vázquez R. (1998). Ética y clonación. Ciencia. Vol.49, No. 2, Junio. Academia Mexicana de Ciencias. México, DF. 5-10.

Watson R.T., Zinyowera M.C. y Moss R. Editores. (1995). Climate Change 1995. Impacts, Adaptations and Mitigation of Climate Change: ScientificT-echnical Analyses. Cambrige Univesity Press. 


\section{Semblanza del autor}

Polioptro F. Martínez-Austria. Es ingeniero civil egresado del Instituto Politécnico Nacional, obtuvo los grados de maestría y doctorado en Ingeniería (Hidráulica) en la Universidad Nacional Autónoma de México. Ha iniciado y consolidado líneas de investigación aplicada, desarrollo y transferencia de tecnología; asimismo, se ha hecho cargo de la planeación, diseño y puesta en marcha de varios grupos y líneas de investigación, en particular, en transporte de contaminantes, saneamiento de cuerpos de agua e ingeniería hidroagrícola. Ha laborado como profesor de licenciatura y posgrado en la Facultad de Ingeniería de la UNAM, en donde ahora imparte el curso de Metodología de la Investigación. Es autor de más de cien artículos técnicos publicados en congresos y revistas nacionales e internacionales en donde presenta contribuciones originales en aspectos básicos, desarrollo de tecnologías apropiadas, hidráulica computacional, hidráulica experimental y gestión del agua. Ha recibido, entre otras distinciones, el Premio Nacional Enzo Levi 2000 a la Investigación y Docencia en Hidráulica y el Premio Miguel A. Urquijo al mejor artículo técnico. Es miembro de la Academia Mexicana de Ciencias, de la Academia de Ingeniería, de la International Association for Hydraulic Research and Engineering y de la International Water Resources Association. Actualmente se desempeña como jefe de la Unidad de Asuntos Fronterizos de la Comisión Nacional del Agua. 